\title{
Establishment of normative data for stretched penile length in Turkish preterm and term newborns
}

\author{
Halit Halil, Şerife Suna Oğuz \\ Division of Neonatology, Zekai Tahir Burak Maternity Teaching Hospital, Ankara, Turkey. \\ E-mail: halidhalil@yahoo.com \\ Received: 1st March 2017, Accepted: 10th March 2017
}

SUMMARY: Halil H, Oğuz ŞS. Establishment of normative data for stretched penile length in Turkish preterm and term newborns. Turk J Pediatr 2017; 59: 269-273.

The aim of this study was to establish a normal range of preterm and term stretched penile length based on their gestational age and anthropometric parameters at birth. A total of 585 infants; 336 (57.43\%) preterm and 249 (42.57\%) term male infants born between August 2015 and September 2016 with gestational age between 26 and 41 weeks were included in our study. Stretched penile length was measured from the pubic ramus to the tip of the glans. Gestational age, stretched penile length and anthropometric parameters at birth (weight, length and head circumference) were recorded within the first three days of life. Variations of stretched penile length in relation to gestational age and anthropometric parameters were evaluated using multiple linear regression models. The mean stretched penile length \pm SD of preterm and term neonates were $2.5 \pm 0.565 \mathrm{~cm}$ and $3.2 \pm 0.551 \mathrm{~cm}$, respectively. In all infants, stretched penile length was significantly affected by gestational age and birth length (OR: 0.079, 95\% CI 0.059-0.098, p=0.0001, OR:0.022, $95 \%$ CI $0.007-0.037, \mathrm{p}=0.005$, respectively). In term infants, stretched penile length was significantly affected by gestational age (OR: $0.139,95 \% \mathrm{CI}$ $0.082-0.196, p=0.0001$ ) and in preterm infants, gestational age and birth length significantly infleuenced the stretched penile length (OR: 0.090, 95\% CI 0.065-0.0115, $\mathrm{p}=0.0001$, OR:0.024, 95\% CI 0.009-0.039, $\mathrm{p}=0.002$, respectively). This study provides reference values of stretched penile length for term and viable preterm Turkish infants.

Key words: stretched penile length, Turkish, preterm infants, term infants.

Examination of the external genitalias is an important step in the routine neonatal examination. Early recognition of penis size abnormalities is important as it might be the first sign of congenital or endocrine disorders like growth hormone deficiency or hypopituitarism or other disorders of sexual differentiation ${ }^{1}$. Penis length (PL) is reported to vary between different races and ethnicities ${ }^{2-5}$. This makes it necessary to establish standard values for penile sizes in healthy neonates in each country. Reference values based on local normative data for penile length (PL) are important predictive factors for the early diagnosis and treatment of potential congenital diseases $^{6}$. Establishing novel reference values for preterm infants is also essential to alert clinicians to diagnose potential hormone abnormalities in premature infants.
Previously published studies from our country $1,7-9$ investigated stretched penile length (SPL) in term new borns, children and adolescents, and to the best of our knowledge, there was no published study on the normal penis size of preterm Turkish infants. The aim of our present study was to estimate a correlation between SPL and weight, length, head circumference and gestational age in Turkish term and preterm newborns extending to the limits of viability.

\section{Material and Methods}

This study was carried out at the neonatology unit of our hospital between August 2015 and September 2016. Patients eligible for this study were live born male infants delivered between 26 and 41 gestational weeks. Non 


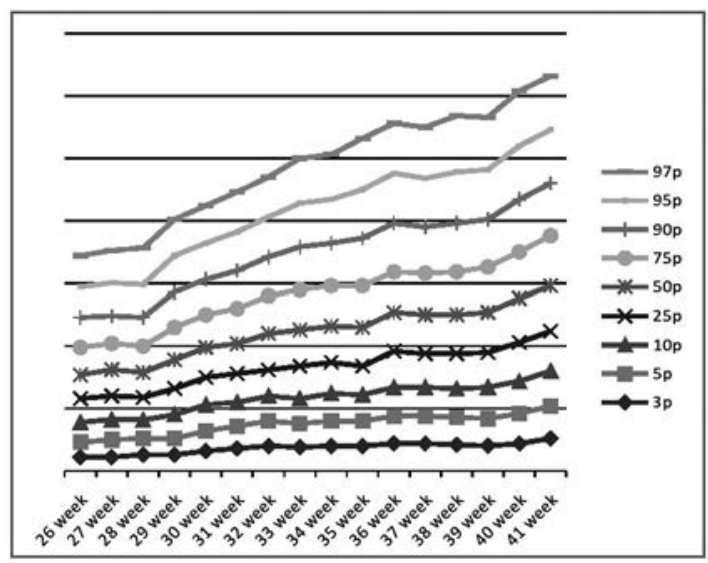

Fig. 1. Stretched Penis Length Percentiles According To Gestational Age

viabile, extremely very low birth weight preterm patients and patients with major congenital malformations, chromosomal anomalies, genital anomalies and endocrine disorders were excluded from this study. The study was approved by the local Ethics Committee of our hospital, approval number: 2015-33. Informed consent were obtained from the parents of the included neonates.

Penile length was determined by the method described by Cinaz ${ }^{1}$. All measurements were performed in the first three days of life in a warm $\left(23-24^{\circ} \mathrm{C}\right)$ and comfortable room for term infants and in their incubators for preterm infants. Penile length measurements of neonates were taken in a supine position with both legs in a flexed position. Fat tissue over the pubic ramus was maximally compressed by a flexible plastic ruler and the penis was stretched by holding the glans between the two fingers of the examinator. The distance between the base of the penis and the tip of the glans was measured. Two consecutive measurements were taken to the nearest millimeter and the mean was recorded.

Birth weight, length, and head circumference of the patients were also measured. Length was measured in the supine position, and weight was measured with a scale sensitive to $10 \mathrm{~g}$. All measurements were recorded by the author .

Gestational age was determined based on the last date of maternal menstruation, fetal ultrasonography findings or the New Ballard Scoring system ${ }^{10}$.

\section{Statistical Analysis}

The data were entered and analysed using the software package SPSS 17.0 (SPSS Inc. Chicago, IL, USA) for Windows. Continuous variables were expressed as mean \pm standard deviation (SD). The 3rd, 5th, 10th, 25th, 50th, 75th, 90th, 95th and 97th percentile values were calculated for SPL measurements. The Pearson's correlation coefficient was used to determine the presence of a linear relationship between SPL measurements and gestational age, birth weight, length and head circumference. Multivariate linear regression analysis was used to explore the variables that influenced SPL measurements. A p-value less than 0.05 was accepted to be statistically significant.

\section{Results}

A total of 585 newborn: $336(57.43 \%)$ preterm and $249(42.57 \%)$ term male infants born between August 2015 and September 2016 with gestaional age between 26 and 41 weeks were included in our study. The mean SPL \pm SD of preterm and term neonates were $2.5 \pm 0.565$ $\mathrm{cm}$ and $3.2 \pm 0.551 \mathrm{~cm}$ respectively. Minimum and maximum SPL in preterm infants were $1.1-4.1 \mathrm{~cm}$ and $2.0-4.5 \mathrm{~cm}$ in term infants (Table I). SPL values according to gestational age is depicted in Table II. The $3^{\text {rd }}, 5^{\text {th }}, 10^{\text {th }}$, $25^{\text {th }}, 50^{\text {th }}, 75^{\text {th }}, 90^{\text {th }}, 95^{\text {th }}$ and $97^{\text {th }}$ percentile values were calculated for SPL measurements according to gestational age and are given in Table III and Figure 1.

Multivariate regression analysis in all infants

Table I. Values of SPL $(\mathrm{cm})$ in Pretem and Term Infants.

\begin{tabular}{lll}
\hline & Preterm & Term \\
\hline Total number of cases $(\%)$ & $336(57.43 \%)$ & $249(42.57 \%)$ \\
Mean \pm SD $(\mathrm{cm})$ & $2.5 \pm 0.565$ & $3.2 \pm 0.551$ \\
Median $(\mathrm{cm})$ & 2.4 & 3.3 \\
Min.-Max. $(\mathrm{cm})$ & $1.1-4.1$ & $2.0-4.5$
\end{tabular}

SPL: stretched penile length, $\mathrm{cm}$ : centimeter, Min: minimum, Max: maximum, SD: Standard deviation 
Table II. Stretched Penis Length (cm) Values According To Gestational Age.

\begin{tabular}{lllllll}
\hline $\begin{array}{l}\text { Gestational } \\
\text { age(week) }\end{array}$ & $\begin{array}{l}\text { Number of } \\
\text { cases }\end{array}$ & Median $(\mathrm{cm})$ & Mean $(\mathrm{cm})$ & SD & Min. $(\mathrm{cm})$ & Max. $(\mathrm{cm})$ \\
\hline 26 & 30 & 1.9 & 1.9 & 0.32 & 1.1 & 2.5 \\
27 & 31 & 2.1 & 2.0 & 0.28 & 1.1 & 2.6 \\
28 & 32 & 2.0 & 1.9 & 0.31 & 1.3 & 2.9 \\
29 & 29 & 2.3 & 2.3 & 0.39 & 1.3 & 2.9 \\
30 & 31 & 2.4 & 2.4 & 0.32 & 1.6 & 3.0 \\
31 & 33 & 2.4 & 2.4 & 0.38 & 1.8 & 3.3 \\
32 & 32 & 2.9 & 2.6 & 0.44 & 2.0 & 3.2 \\
33 & 28 & 2.9 & 2.8 & 0.45 & 1.9 & 3.4 \\
34 & 30 & 2.9 & 2.8 & 0.43 & 2.0 & 3.6 \\
35 & 29 & 3.1 & 2.9 & 0.61 & 2.0 & 4.1 \\
36 & 31 & 3.1 & 3.0 & 0.50 & 2.2 & 4.0 \\
37 & 29 & 3.1 & 3.0 & 0.47 & 2.2 & 4.1 \\
38 & 44 & 3.1 & 3.1 & 0.54 & 2.1 & 4.5 \\
39 & 82 & 3.2 & 3.2 & 0.55 & 2.0 & 4.2 \\
40 & 65 & 3.5 & 3.4 & 0.53 & 2.2 & 4.4 \\
41 & 29 & 3.6 & 3.5 & 0.47 & 2.6 & 4.3 \\
\hline
\end{tabular}

$\mathrm{cm}$ : centimeter, Min: minimum, Max: maximum, SD: Standard deviation

showed gestational age and birth length significantly affecting SPL (OR: 0.079, 95\% CI $0.059-0.098, p=0.0001$, OR:0.022, 95\% CI $0.007-0.037, \mathrm{p}=0.005$, respectively). In preterm infants, gestational age and birth length significantly infleuenced SPL (OR: 0.090, 95\% CI 0.065-0.0115, $\mathrm{p}=0.0001$, OR:0.024, 95\% CI 0.009-0.039, $\mathrm{p}=0.002$ respectively). In term infants, SPL was significantly affected by gestational age (OR: $0.139,95 \%$ CI $0.082-$ $0.196, \mathrm{p}=0.0001)$.

\section{Discussion}

To the best of our knowledge, this was the first study from Turkey that established a normative data for stretched penile length of viable preterm infants. We aimed to estimate a relationship between SPL and anthropometric parameters of the newborn infants according to their gestational age and to compare our findings with other studies on infants born in different countries. In our present study, we found that the mean SPL \pm SD of preterm and term neonates were $2.5 \pm 0.565 \mathrm{~cm}$ and $3.2 \pm$ $0.551 \mathrm{~cm}$, respectively. Minimum and maximum ranges of SPL in preterm infants were 1.1-4.1 $\mathrm{cm}$ and $2.0-4.5 \mathrm{~cm}$ in term infants.
There were few studies on SPL measurement from our country. Consisted with our study, Akın et al. ${ }^{8}$ reported that the mean SPL of 1217 Turkish term infants was $3.16 \pm 0.39 \mathrm{~cm}$ and the lower and upper limits were $2.19-4.14 \mathrm{~cm}$. Cinaz et al. ${ }^{1}$ conducted the most comprehensive study in this field from four different centres in Turkey. They determined the mean penile length and established the percentile curves of 1278 Turkish children from newborn to prepubertal period. The mean penile length of the term neonates was $3.64 \pm 0.36 \mathrm{~cm}$ with the minimum and maximum SPL range of 2.7 and $4.5 \mathrm{~cm}$. Another study from Turkey conducted by Kutlu et al. ${ }^{7}$, they measured the SPL of 514 term neonate and found that the SPL of term neonates was $3.77 \pm 0.35 \mathrm{~cm}$. Previous studies from our country showed great differences in penile length at birth ranging from 3.16 to $3.77 \mathrm{~cm}^{1,7}$. There were also some differences between the findings of our study and previously reported studies from Turkey ${ }^{1,7}$. Differences in penile measurements as great as $0.5 \mathrm{~cm}$ have been reported by authors from the same countries ${ }^{12-13}$. SPL measurements can be influenced by many factors like penis erection, patient body temperature, room temperatur and personel measurement factors $7,12-13$. Three 
Table III. Stretched Penis Length(cm) Percentiles(p) According To Gestational Age.

\begin{tabular}{llllllllll}
\hline $\begin{array}{l}\text { Gestational } \\
\text { age(week) }\end{array}$ & $3 p$ & $5 p$ & $10 p$ & $25 p$ & $50 p$ & $75 p$ & $90 p$ & $95 p$ & $97 p$ \\
\hline 26 & 1.1 & 1.2 & 1.6 & 1.9 & 1.9 & 2.2 & 2.4 & 2.4 & 2.5 \\
27 & 1.1 & 1.4 & 1.62 & 1.9 & 2.1 & 2.1 & 2.2 & 2.6 & 2.6 \\
28 & 1.3 & 1.3 & 1.5 & 1.8 & 2.0 & 2.1 & 2.3 & 2.6 & 2.9 \\
29 & 1.3 & 1.3 & 1.9 & 2.1 & 2.3 & 2.6 & 2.8 & 2.9 & 2.9 \\
30 & 1.6 & 1.6 & 2.1 & 2.2 & 2.4 & 2.6 & 2.8 & 2.9 & 3.0 \\
31 & 1.8 & 1.8 & 1.9 & 2.3 & 2.4 & 2.8 & 3.0 & 3.1 & 3.2 \\
32 & 2.0 & 2.0 & 2.0 & 2.1 & 2.9 & 3.0 & 3.1 & 3.2 & 3.2 \\
33 & 1.9 & 1.9 & 2.0 & 2.6 & 2.9 & 3.2 & 3.4 & 3.5 & 3.6 \\
34 & 2.0 & 2.0 & 2.2 & 2.5 & 2.9 & 3.2 & 3.4 & 3.5 & 3.6 \\
35 & 2.0 & 2.0 & 2.1 & 2.3 & 3.1 & 3.3 & 3.8 & 3.9 & 4.1 \\
36 & 2.2 & 2.2 & 2.3 & 2.9 & 3.1 & 3.2 & 3.9 & 4.0 & 4.0 \\
37 & 2.2 & 2.2 & 2.3 & 2.7 & 3.1 & 3.3 & 3.7 & 3.9 & 4.1 \\
38 & 2.1 & 2.2 & 2.3 & 2.8 & 3.1 & 3.4 & 3.9 & 4.1 & 4.5 \\
39 & 2.0 & 2.2 & 2.5 & 2.8 & 3.2 & 3.6 & 3.8 & 4.0 & 4.2 \\
40 & 2.2 & 2.4 & 2.6 & 3.1 & 3.5 & 3.7 & 4.2 & 4.3 & 4.4 \\
41 & 2.6 & 2.6 & 2.8 & 3.2 & 3.6 & 4.0 & 4.2 & 4.3 & 4.3 \\
\hline
\end{tabular}

P: Percentiles

Table IV. Multivariate Regression Analysis of Parameters Affecting Penile Length in Newborns.

\begin{tabular}{|c|c|c|c|c|c|}
\hline & \multirow{2}{*}{ Independent variables } & \multirow{2}{*}{ Adjusted odds ratio } & \multicolumn{2}{|c|}{ 95\% Confidence Interval } & \multirow[t]{2}{*}{$P$} \\
\hline & & & Lower & Upper & \\
\hline \multirow[t]{2}{*}{ All infants } & Gestational age (week) & 0.079 & 0.059 & 0.098 & 0.0001 \\
\hline & Birth length(cm) & 0.022 & 0.007 & 0.037 & 0.005 \\
\hline $\begin{array}{l}\text { Term } \\
\text { infants }\end{array}$ & Gestational age (week) & 0.139 & 0.082 & 0.196 & 0.001 \\
\hline Preterm & Gestational age (week) & 0.090 & 0.065 & 0.115 & 0.001 \\
\hline infants & Birth length $(\mathrm{cm})$ & 0.024 & 0.009 & 0.039 & 0.002 \\
\hline
\end{tabular}

Values of $\mathrm{P}<0.05$ were considered significant.

studies from different regions of India also showed great differences in penile length mesurements ranging from 2.31 to $3.57 \mathrm{~cm}^{2,12-}$ 13. To decrease the errors of our measurements and to increase the reliability of our study, all measurements were performed and recorded by the author in a warm and comfortable enviroment for all infants.

Recent studies from different countries and geographical areas reported different values of SPL in newborn infants. It was found that the mean penile lengths was $3.2 \pm 0.3 \mathrm{~cm}$ in Iranians ${ }^{4}, 3.06 \pm 0.26 \mathrm{~cm}$ in Japanese full-term newborn infants ${ }^{3}, 3.4 \pm 0.37 \mathrm{~cm}$ in Egyptian male newborns ${ }^{6}$ and $2.86 \pm 0.23 \mathrm{~cm}^{3}$ in China ${ }^{14}$. The difference in these results showed that the penile length values varies according to geographical areas, countries and ethnic origin of the newborns.

Multivariate regression analysis of our study showed that SPL was significantly affected by gestational age in term infants and by gestational age and birth length in preterm infants. Different studies from our country ${ }^{1,7-8}$ investigated the correlation between SPL and the anthropometric measurements of children. 
Cinaz et al. ${ }^{1}$ reported a significant relation between SPL and age, height, body weight and height age in all children. Akın et al. ${ }^{8}$ found only a correlation between SPL and body height whereas, Kutlu et al. ${ }^{7}$ concluded that SPL was positively correlated with height and head circumference of all children included in their study.

Early recognition of penile disorders in the neonatal period is important because it may be the only sign of pituitary or hypothalamic hormone abnormalities that requires early diagnosis, further investigation and treatment of an underlying disorder ${ }^{1,15-16}$. In our present study we included 336 preterm infants extending to the limits of viability. We found the mean SPL of preterm neonates was $2.5 \pm$ $0.565 \mathrm{~cm}$ and the minimum and maximum SPL of preterm infants was $1.1-4.1 \mathrm{~cm}$. We find that the SPL was significantly infleuenced by the gestational age and by the birth length of the preterm neonates. We also determined the $3^{\text {rd }}$, $5^{\text {th }}, 10^{\text {th }}, 25^{\text {th }}, 50^{\text {th }}, 75^{\text {th }}, 90^{\text {th }}, 95^{\text {th }}$ and $97^{\text {th }}$ percentile of the SPL of the preterm infants. As far as we know, this was the first study from Turkey that investigated the stretched penile length of the preterm infants, and there was not any published study on this field. Our aim was to establish a normative data for viable preterm Turkish infants according to their gestational age and to estimate a correlation between SPL and their anthropometric measurements at birth. Our findings may help the professionals to recognize penis size abnormalities durring the routine neonatal examination that might be a clue to prompt congenital or endocrine disorders.

As a conclusion, this study provided reference values of stretched penile length for term and viable preterm Turkish infants. Limitations of our study are that we only measured the penile length. However, we did not investigate the penis circumferences of preterm and term infants. The penis of the newborn infants is not uniformly cylindrical in shape, the measurement of the circumferences at different sites like corona or mid-shaft may not be the representative of the true circumferences of the penis ${ }^{2}$. To increase the reliability analysis of our study and to decrease the errors of measurements we excluded the measurements of penis circumferences from our study

\section{REFERENCES}

1. Cinaz P, Yeşilkaya E, Onganlar YH, Boyraz M, Bideci A, Camurdan O, Karaoğlu AB. Penile anthropometry of normal prepubertal boys in Turkey. Acta Paediatr 2012; 101: 33-36.

2. Bhat A, Upadhyay R, Bhat M, Sabharwal K, Singla M, Kumar V. penile anthropometry in North Indian children. Indian J Urol 2015; 31: 106-110.

3. Matsuo N, Ishii T, Takayama JI, Miwa M, Hasegawa T. Reference Standard of penile size and prevalence of buried penis in Japanese newborn male infants. Endocr J 2014; 61: 849-853.

4. Alaee E, Gharib MJ, Fouladinejad M. Penile length and anogenital distance in male newborns from different Iranian ethnicities ingolestan province. Iran Red Crescent Med J 2014; 25: 1-4

5. Park JY, Lim G, Oh KW et al. Penile length, digit length, and anogenital distance according to birth weight in newborn male infants. Korean J Urol 2015; 56: $248-253$.

6. El Kholy M, Hamza RT, Saleh M, Elsedfy H. Penile length and genital anomalies in Egyptian male newborns: epidemiology and influence of endocrine disruptors. J Pediatr Endocrinol Metab 2013; 26: 509513.

7. Kutlu AO. Normative data for penile length in Turkish newborns. J Clin Res Pediatr Endocrinol 2010; 2: 107110.

8. Akin Y, Ercan O, Telatar B, Tarhan F. Penile size in term newborn infants. Turk J Pediatr 2011; 53: 301307.

9. Camurdan $\mathrm{AD}, \mathrm{Oz} \mathrm{MO}$, Ilhan $\mathrm{MN}$, Camurdan $\mathrm{OM}$, Sahin F, Beyazova U. Current stretched penile length: cross-sectional study of 1040 healthy Turkish children aged 0 to 5 years. Urology 2007; 70: 572-575.

10. Ballard JL, Khoury JC, Wedig K, Wang L, EilersWalsman BL, Lipp R. New Ballard Score, expanded to include extremely premature infants. J Pediatr 1991; 119: 417-423.

11. Cole TJ, Green PJ. Smoothing reference centile curves: The LMS method and Penalized Likelihood. Stat Med 1992; 11: 1305-1319.

12. Kulkarni ML, Rajendran NK. Normal values for penile standards in newborns. Indian Pediatr 1991; 28: 13411343.

13. Vasudevan G, Manivarmane B, Bhat BV, Bhatia BD, Kumar S. Genital standards for south Indian male newborns. Indian J Pediatr 1995; 62: 593-596.

14. Sutan-Assin M, Rukman J, Dahlan A. Penis dimensions of newborn infants. Paediatr Indones 1989; 29: 146-150.

15. Hatipoğlu N, Kurtoğlu S. Micropenis: etiology, diagnosis and treatment approaches. J Clin Res Pediatr Endocrinol 2013; 5: 217-223.

16. Cimador M, Catalano P, Ortolano R, Giuffrè M. The inconspicuous penis in children. Nat Rev Urol 2015; 12: 205-215. 